\title{
Flexibilização do Trabalho e Mobilidade Geográfica nas Forças Armadas
}

\section{Resumo}

O texto apresenta resultados de uma pesquisa sobre as perceções de um grupo de trabalhadores que integram um segmento periférico das Forças Armadas portuguesas, contratados a termo e em situação de mobilidade geográfica mensal. Procurou conhecer os impactos destes tipos de flexibilidade nas forças armadas sobre as suas expetativas e estratégias profissionais e pessoais. Foram utilizados inquéritos por questionário e entrevistas semiestruturadas. Verificou-se a existência de precaridade de emprego e de trabalho, que são fontes de insatisfação; sentimento de segmentação laboral relativamente ao núcleo-duro; dificuldades de conciliação e de acesso a formação. Concluiu-se que os desafios para a organização militar são bastantes, com uma força de trabalho que tende a apresentar-se desmoralizada pela precariedade, pela sensação de rotina, fadiga e impossibilidade de progressão. Para os indivíduos, a consciência de "trabalhador nómada" começa a pesar, com as deslocações constantes, com a aproximação do fim do contrato e com a necessidade de preparação para a reintegração no mercado de trabalho. A precariedade é hoje experienciada num dos setores que ainda há pouco se considerava dos mais estruturados e que garantia permanência e estabilidade de carreira, o militar, e que hoje é também já um local de "passagem" dos seus "profissionais".

Palavras-chave: Flexibilização Laboral. Precariedade. Mobilidade Geográfica; Forças Armadas.

\footnotetext{
Universidade de Coimbra e Instituto Superior Miguel Torga (Portugal).

${ }^{* *}$ Instituto Superior Miguel Torga (Portugal).

*** Universidade de Coimbra e Instituto Superior Miguel Torga (Portugal).
} 


\title{
Labor Flexibilization and Geographical Mobility in the Armed Forces
}

\begin{abstract}
The paper presents results of a survey on the perceptions of a group of workers who are part of a peripheral segment of the Portuguese Armed Forces hired on a fixed-term basis and subjected to constant geographical mobility. It explores the impacts of such flexibility in work practices in the armed forces on their professional and personal expectations and strategies. A questionnaire and semi-structured interviews were used. We observed the existence of employment and labor precariousness, which are sources of dissatisfaction; feelings of labor segmentation with respect to mainstream groups within army; difficulties in reconciliation and access to training. It was concluded that there are several challenges to the military organization, with a workforce that tends to be demoralized by insecurity, by a sense of routine, fatigue and inability to progression. For individuals, the sense of "nomadic worker" begins to weigh due to constant moving, to the approaching of contract termination and the need to prepare for reintegration into the labor market. Such precariousness is observed in a sector that until recently was seen as one of the best structured and that used to guarantee stability - the military career - and that now becomes also a place of "passage" for their "professionals".
\end{abstract}

Keywords: Labor Flexibility. Precariousness. Geographical Mobility. Armed Forces.

\section{Introdução}

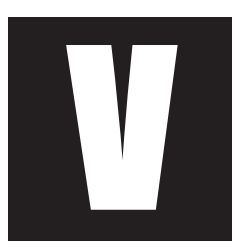

erifica-se atualmente uma mudança do modelo de regulação fordista, com a expansão de modalidades de emprego e de vínculo contratual antes consideradas atípicas. É o caso do trabalho temporário, dos contratos a termo, a tempo parcial e do trabalho independente. É também o caso de novas formas de mobilidade que se impõem sobre a força de trabalho como adaptação às necessidades do mercado de traba- 
Sociologias, Porto Alegre, ano 17, oo 38, jan/abr 2015, p. 222-253

Iho, designadamente a mobilidade funcional e geográfica. Apresentadas como formas de flexibilização pós taylorista por parte das organizações, na realidade estas novas formas de trabalho encerram dimensões de precarização que importa compreender. Esse é o objetivo do estudo aqui apresentado, que analisa as perceções de um grupo específico de trabalhadores, que integram um segmento periférico das Forças Armadas portuguesas, porque contratados a termo e em situação de mobilidade geográfica mensal. Trata-se do grupo de 42 oficiais divulgadores inseridos no Projeto do Dia da Defesa Nacional (PDDN). Este grupo é constituído por jovens, que possuem um contrato a termo e que mensalmente se deslocam por Centros, em regiões distintas do país, ministrando ações de divulgação e informação aos jovens que completam 18 anos. A situação destes profissionais traduz o processo de mudança vivido nas Forças Armadas portuguesas nas décadas de 1990 e 2000, com o fim do serviço militar obrigatório e o início do processo de profissionalização (de 1993 para 2005 o número de oficiais reduziu-se em cerca metade, passando de 78000 para 37 000) (Cardoso et al., 2009).

O recurso ao trabalho a termo, nascido na generalidade dos países europeus na década de 1950, como uma forma marginal de emprego, acentuou-se a partir de meados da década de 1970, apresentando-se atualmente como forma flexível de emprego dominante. Este tipo de contrato designa um trabalho por natureza provisório e consequentemente precário, pois evidencia a instabilidade e a incerteza do vínculo contratual. O estudo explorou as perceções das pessoas desta equipa relativamente à sua situação laboral, procurando conhecer os impactos deste tipo de trabalho flexível (vínculo contratual e mobilidade geográfica) sobre as suas expetativas e estratégias profissionais, a sua vida e projetos familiares, também sobre o acesso a formação profissional e académica, as condições de remuneração e de desenvolvimento profissional. Um dos 
Sociologias, Porto Alegre, ano 17, no 38, jan/abr 2015, p. 222-253

aspetos interessantes diz respeito à comparação que se estabelece necessariamente entre estes oficiais das forças armadas e o outro segmento de oficiais, com vínculo permanente.

\section{Flexibilização e precariedade laboral}

No início dos anos 1970, a pressão do "choque petrolífero" impôs, às empresas e estados ocidentais, novos modelos organizacionais, face à obsolescência dos equipamentos e dos processos existentes (Boyer, 1986). O sistema flexível surgiu como uma possível resposta para superar a rigidez do modelo taylorista-fordista (Castells, 1999), propagandeado como oportunidade para trabalhadores e empresas pela orientação neoliberal (Kovács, 2013). Nas décadas de 1980 e 1990, intensificou-se a retórica da flexibilidade, apresentada como um dos mais importantes motores de desenvolvimento produtivo das organizações, quer na sua aplicação às políticas de gestão dos recursos humanos, quer às políticas de produção. Têm sido promovidas medidas de abertura dos mercados, desregulamentação da economia, privatização dos setores estratégicos e serviços públicos, liberalização do mercado de trabalho, redução da proteção social, e individualização das relações laborais. Fala-se mesmo de uma nova construção social do trabalho e do tempo de trabalho (Cardoso, 2013). A flexibilidade passou a significar multiplicação de formas de contratação, bem como vicissitudes da relação individual de trabalho (variação dos horários de trabalho, de tipos de vínculo e de proteção social; mobilidade funcional, mobilidade geográfica); e até a multiplicidade de formas de cessação do contrato de trabalho.

É hoje reconhecida a necessidade de questionar a noção idealizada de flexibilidade, porque as situações e práticas que em seu nome são implementadas não têm necessariamente consequências positivas para 
Sociologias, Porto Alegre, ano 17, oo 38, jan/abr 2015, p. 222-253

quem trabalha (Beck, 2000; Boltanski e Chiapello, 1999; Boyer, 1986; Casaca, 2005; Castel, 1995; Kovács, 2013; Kovács e Casaca, 2007; Pedaci, 2010; Tilly, 1976). Aliás, sem afastar a possibilidade de existirem aspetos positivos na flexibilidade, porque são várias as suas faces (sinónimo de maior autonomia individual, participação e fim do taylorismo), a questão que aqui se pretende realçar é a de que ela encerra em si mesmo contradições e limitações geradoras de novas formas de insegurança, de injustiça e de precariedade.

As atuais práticas de flexibilidade assentam, dominantemente, em esquemas de flexibilização numérica ou contratual (trabalho temporário ou a termo certo) e temporal ou financeira (diversificação e imprevisibilidade dos horários de trabalho e individualização dos salários), recorrendo-se muito pouco à flexibilidade funcional (esbatimento das estruturas hierárquicas, polivalência) e registando-se uma expansão considerável do trabalho temporário, dos contratos a termo e do trabalho independente (Goudswaard e Nanteuil, 2000).

Numa abordagem não determinista desta problemática, tem sido sustentado que a flexibilidade no trabalho tanto pode conter riscos como oportunidades. Do lado dos riscos salientam-se a precariedade de emprego, a segregação no mercado de trabalho, as remunerações baixas e irregulares, a desqualificação e falta de oportunidades de desenvolvimento profissional, formação e carreira, os conflitos com a vida familiar e o agravamento das desigualdades e assimetrias sociais. Do lado das oportunidades, salienta-se a possibilidade de uma participação laboral mais adequada às necessidades e aspirações individuais, melhoria das qualificações, acesso a empregos bem remunerados, melhor conciliação com a vida familiar/pessoal, maior controlo sobre o tempo, entre outras (Casaca, 2005; Kovács, 2005). Tendo em conta esta dupla faceta das situações laborais flexíveis, neste estudo pretendeu-se que as pessoas entrevistadas 
refletissem acerca das vantagens e desvantagens que experienciam na sua situação. Colocou-se como primeira hipótese a de que na reflexão que fazem acerca da sua situação, os militares do PDDN apresentem juízos complexos acerca desta experiência profissional, conjugando dimensões de ganho, nomeadamente o emprego e a remuneração numa época de escassez destes bens, com dimensões de perda, tendo em conta a fragilidade do vínculo contratual, a mobilidade geográfica permanente e instabilidade, e dificuldades de conciliação. É importante referir que esta é uma experiência partilhada com a sua geração, tendo em conta que em Portugal a inserção dos jovens, mesmo os que possuem um elevado nível de escolaridade, tem sido marcada pela precariedade.

Paugam (2000) é um dos autores que mais tem refletido acerca da precariedade laboral. Introduziu uma heurística distinção entre precariedade no emprego, relacionada com o estatuto social e legal (contratual) inerente à situação de emprego, e precariedade no trabalho, que invoca uma necessidade de análise compreensiva e qualitativa das condições de trabalho, designadamente, as dimensões subjetivas e as trajetórias individuais. A junção de ambas as dimensões de precariedade conduz a uma situação de vulnerabilidade no mercado de trabalho e na sociedade em geral, isto é, ao risco de precariedade social, delineando-se a insatisfação laboral e a instabilidade de emprego também como dimensões importantes da precariedade. Já para Barbier (2002), a precariedade no trabalho também pode ser analisada à luz de duas dimensões: a objetiva e a subjetiva. Sendo que a precariedade objetiva está mais relacionada com as relações contratuais não permanentes (contratos a termo certo e incerto), isto não quer dizer que o contrato sem termo seja o reverso da precariedade. Na verdade, apesar de a pessoa saber que tem um emprego garantido, pode ser precário relativamente às suas funções, ao seu conteúdo, às condições penosas de trabalho (risco para a saúde física ou 
Sociologias, Porto Alegre, ano 17, oo 38, jan/abr 2015, p. 222-253

psicológica), ao desenvolvimento profissional, à remuneração, entre outras. A dimensão subjetiva está, portanto, relacionada com o grau de (in) satisfação com as condições de trabalho em geral, com as motivações e recompensas intrínsecas decorrentes da situação de trabalho.

A precariedade está assim relacionada, também, com as condições de trabalho, nomeadamente, com o desempenho de funções de pobre conteúdo, por vezes, pouco valorizadas no mundo organizacional, produtoras de insatisfação, com efeitos na saúde psicológica e física dos trabalhadores e com as fracas ou nulas oportunidades de formação e de desenvolvimento profissional, dimensões que exploramos neste trabalho. Resumindo, a precariedade no emprego e no trabalho podem acumular-se e serem uma fonte de sofrimento, de insegurança, de crise identitária e de incerteza face ao futuro. Por isso, neste estudo colocou-se como segunda hipótese que a situação contratual temporária será um fator determinante da precariedade no emprego e as caraterísticas do conteúdo de trabalho, a falta de expetativas e possibilidade de progressão, bem como a mobilidade geográfica permanente contribuirão para as perceções de precariedade no trabalho.

O caráter voluntário de algumas formas de trabalho flexível, não as desvincula do epíteto de trabalho precário; antes revela uma "escolha" condicionada por fatores que fazem dela "o mal menor", face a um mercado de trabalho que exclui os jovens e os relega para trabalhos flexíveis e mal pagos. Até que ponto esta "precariedade" é melhor do que "as outras" foi um dos aspetos aqui explorados, procurando compreender as razões que condicionam e justificam esta opção. Colocou-se como terceira hipótese a interiorização de uma identidade de trabalhadores "descartáveis" (Fialho, Silva e Saragoça, 2011) ou "nómadas" (Boltanski e Chiapello, 1999) por parte destes jovens, e uma certa acomodação à ideia 
de "precariedade" numa "era de crise da quantidade de trabalho", onde as pessoas se sujeitam a precárias condições de trabalho (Cabral, 2011).

Na sequência da flexibilização e da precarização, constituíram-se dois grupos de trabalhadores: os do "centro" que trabalham em tempo integral, com emprego mais estável, benefícios sociais e outras vantagens; e os da "periferia" com vínculo contratual precário, por tempo determinado, ou em regime de subcontratação e em atividades de trabalho temporário, sem segurança no emprego (Harvey, 1996). Esta segmentação dos trabalhadores terá impactos nas perceções e relações entre uns e outros, elemento que se procurou analisar também junto deste grupo de "trabalhadores da periferia". Marques (2009) estudou o estilhaçar de solidariedades entre ambos os grupos numa empresa industrial em consequência da segmentação. Também Goudswaard e Nanteuil (2000) concluíram que a diferenciação entre os dois segmentos de trabalhadores não se estabelece ao nível das condições de trabalho, mas resulta essencialmente ao nível das condições de emprego. Colocou-se por isso como quarta hipótese que, não obstante partilharem com os militares do quadro o estatuto de militar e igualdade em termos de algumas condições materiais de trabalho, existirá um sentimento de desigualdade entre os militares contratados ("periferia") e os dos quadros permanentes ("centro"), com dimensões materiais e simbólicas específicas, essencialmente ligadas à precariedade do vínculo.

Outra dimensão importante da precariedade, com a incerteza e instabilidade impostas pelo vínculo contratual precário e temporário, prende-se com os impactos nas expetativas e na gestão das fases do ciclo de vida (Kovács, 2013). As pessoas sentem a sua vida marcada por crescentes inconstâncias, flutuações, descontinuidades, movimentos de vaivém: ora têm um emprego, ora ficam desempregadas; adiam planos pessoais; mudam de residência frequentemente. Esta "vida de incons- 
Sociologias, Porto Alegre, ano 17, oo 38, jan/abr 2015, p. 222-253

tâncias" influencia a forma como as pessoas organizam o trabalho profissional, a educação/formação e a família. Há autores que mencionam mesmo uma "ressimbolização do espaço social do trabalho", marcada por uma valorização da "cultura de risco" (Beck, 2000), pela acomodação da precariedade, da flexibilidade e da multiatividade, condicionando uma nova atitude perante o trabalho. As experiências de transição dos jovens de hoje diferem profundamente das experiências das gerações anteriores (Anderson et al., 2002), podendo estas acomodar a precariedade como algo de menos atípico. Os percursos profissionais prevalecentes nos trinta anos do pós-guerra, pautados por uma certa continuidade, estabilidade e homogeneidade, dão lugar a percursos descontínuos, incertos, diferenciados e individualizados.

A apologia da mudança e da mobilidade, do "trabalhador nómada" e do "trabalhador descartável" (Fialho et al. 2011), da incerteza em todas as áreas, inerente a este tipo de retórica, inscreve-se no novo espírito do capitalismo (Boltanski e Chiappello, 1999). Neste plano discursivo de construção das identidades, tende a ganhar força a ideia de que se está a assistir à emergência de um mercado de trabalho onde todos serão móveis, poderão livremente valorizar as suas competências e desenvolver carreiras "sem fronteiras", deixando abertas todas as possibilidades, mas também todas as incertezas e inseguranças. Estas circunstâncias impossibilitam a definição de um percurso profissional e identitário coerente, que se previu, na quinta hipótese, ser também uma realidade nos discursos dos jovens militares entrevistados. Instabilidade essa articulada com um sentimento de necessidade de adaptação e de autoresolução, "fluidez" crescente das identidades individuais, adaptáveis à instabilidade do contexto. Nesta linha, as pessoas entrevistadas poderão revelar um individualismo-fragilização, seres isolados submetidos à insegurança, desfiliação e fragilização do laço social e das relações sociais (Kóvacs, 2005). A exal- 
Sociologias, Porto Alegre, ano 17, no 38, jan/abr 2015, p. 222-253

tação da responsabilidade individual é uma marca dos tempos que correm, como principal elemento de mobilização dos recursos humanos ao serviço das organizações (Kovács, 2005), são eles que alimentam as atuais retóricas do empreendedorismo e da empregabilidade permanente.

\section{Precariedade e mobilidade geográfica e os seus impactos}

A mobilidade pode ter uma dimensão geográfica, quando se trata da disponibilidade de um dado trabalhador para aceitar um emprego que implica mudança do local de residência ou deslocações constantes; pode dizer respeito à mobilidade de emprego (rotação de emprego), quando abrange situações em que um trabalhador muda de emprego e, concomitantemente, de entidade empregadora; ou, ainda, reportar-se à mobilidade profissional (Casaca, 2005).

Segundo Coppin e Vandenbrande (2007) a análise da mobilidade geográfica deve, pelo menos, incluir informações acerca de três aspetos: as caraterísticas do trabalhador (idade, sexo, estrutura familiar, país de origem, habilitações literárias, experiência/percurso profissional); as caraterísticas do trabalho (ocupação/posto, setor de atividade, tipo de contrato, oportunidades no trabalho e na formação/aprendizagem); e a relação entre trabalhador/a e organização (atitudes, comportamentos e experiência relativamente às condições exigidas pelo trabalho), elementos explorados nesta investigação.

A precariedade e a mobilidade geográfica levam à incerteza e à instabilidade e têm repercussões nas várias esferas da vida, nomeadamente, na vida pessoal/familiar, na formação/desenvolvimento profissional (educação), nas atividades de lazer (tempos livres) e até na saúde (Green e Canny, 2003). 
Sociologias, Porto Alegre, ano 17, no 38, jan/abr 2015, p. 222-253

Tem-se demonstrado que a mobilidade geográfica exigida pelo mundo laboral pode afetar a saúde devido aos "estados de humor negativos" provocados pelo trabalho (Grzywacz, Almeida e McDonald, 2002) e aos efeitos da competição na utilização dos recursos, como, por exemplo, o tempo disponível para o exercício concomitante dos vários papéis de vida, o que pode causar elevados níveis de stresse (Carlson e Kacmar, 2000; Frone, 2000; Green e Canny, 2003).

Relativamente à conciliação trabalho-família, as pessoas têm cada vez mais dificuldade em encontrar tempo e energia para os vários compromissos nas duas esferas. Em tempos de intensa participação de homens e muIheres no mercado de trabalho (que implica cada vez mais horários atípicos e associais), mas em que persistem assimetrias profundas de papéis sexuais na família, procurou compreender-se os impactos da mobilidade geográfica dos membros da equipa do PDDN sobre a conciliação da sua vida pessoal, familiar e profissional. Evidencia-se ainda a condicionante de o estudo ter sido realizado num contexto laboral onde as mulheres só conseguiram uma porta aberta há cerca de 30 anos. Trata-se da instituição militar, uma das instituições sociais mais prototipicamente masculina (Segal, 1995). Em Portugal, se desde os anos 1960 se podem encontrar algumas mulheres na vida militar, nomeadamente, na Força Aérea, foi apenas no início dos anos 1990 que as mulheres tiveram possibilidade de, em regime voluntário, se candidatarem à prestação de serviço militar. A hipótese seis previu, assim, que não obstante a evolução representada pela entrada de mulheres no trabalho militar, prevalecerão representações que continuam a reforçá-lo como mundo mais adequado para o sexo masculino, devido às maiores dificuldades de conciliação por parte das mulheres. 


\section{Material e métodos}

O PDDN decorre em 12 Centros de Divulgação de Defesa Nacional (CDDN's), sedeados em unidades militares dos três ramos das Forças Armadas portuguesas, distribuídas pelo país. É um Projeto que se desenrola durante todo o ano e visa sensibilizar os jovens para a temática da Defesa Nacional e o papel das Forças Armadas. A comparência ao DDN é um dever militar obrigatório para todos os cidadãos portugueses que cumpram 18 anos (a falta não justificada é punível por lei e inibe para o exercício de funções públicas). Os cidadãos que participam no DDN são recebidos e acompanhados pelos jovens oficiais da equipa em estudo.

Em cada CDDN operam entre 5 a 9 elementos, dos três ramos das Forças Armadas, de ambos os sexos. Estas pessoas são militares da categoria de oficial e prestam serviço em Regime de Contrato (RC), ou seja, possuem uma forma de contratação subordinada de duração determinada, que, regra geral, tem um período mínimo de 2 anos obrigatórios e é prorrogável até ao máximo de 6 anos, findo os quais a pessoa tem remotas ou mesmo nulas oportunidades de continuar no mundo militar.

O desenvolvimento deste trabalho teve como propósito compreender o modo como os membros da equipa em estudo percecionam as particularidades (mobilidade geográfica e precariedade laboral) do tipo de trabalho que executam. Elaborou-se e aplicou-se um inquérito por questionário, aplicado entre janeiro e março de 2013, tendo respondido todos os 42 membros da equipa em estudo. Foram também efetuadas 10 entrevistas individuais semiestruturadas de forma a complementar os dados recolhidos no questionário. Elaborou-se um guião de entrevista, a partir do modelo de análise formulado. As entrevistas duraram entre $30 \mathrm{e}$ 60 minutos e foram realizadas nos meses de março e abril de 2013. Todas as entrevistas foram gravadas e transcritas integralmente. Os dados recoIhidos no inquérito por questionário foram analisados através do software 
Sociologias, Porto Alegre, ano 17, no 38, jan/abr 2015, p. 222-253

SPSS19. Já os dados obtidos em entrevista foram analisados com recurso ao MAXQDA10, e sujeitos a análise de conteúdo categorial.

O PDDN é constituído por 42 divulgadores, da categoria de oficiais, dos três ramos das Forças Armadas. Requisitos de admissão são a detenção de curso superior concluído e idade inferior a 27 anos. A média de idades da amostra é de 29,2 anos, com um desvio-padrão de \pm 1,9 anos. Todas as pessoas possuem um curso superior, sendo que 2 delas possuem também um mestrado/curso de 20 ciclo. A maioria tem como área base de formação as ciências sociais. Quinze pessoas provêm do ramo do Exército, catorze da Força Aérea e treze da Marinha. Geograficamente, os 42 divulgadores residem em diversas zonas de Portugal Continental, sendo que $42,9 \%$ são da região da Grande Lisboa.

Verificou-se ainda que a maioria (25) são homens (59,5\%) e 17 são mulheres (40,5\%); já quanto ao estado civil $69 \%$ são solteiros/as, 14,3\% são casados/as, maioritariamente as mulheres, e 14,3\% vivem em união de facto. Cinco pessoas já têm filhos, todos com idades inferiores a 5 anos. Existe, portanto, uma predominância do sexo masculino e de pessoas solteiras. Relativamente à antiguidade predominam as pessoas com menos tempo de serviço, ou seja, com menos de 2 anos. Contudo, antes de ingressarem no mundo militar e concretamente no PDDN, grande parte destas pessoas exerceram funções profissionais no mundo do trabalho civil (76,2\%). Das 17 mulheres, por exemplo, apenas uma não exerceu nenhuma profissão anterior à vida militar, contrariamente aos homens (9 tiveram como primeira experiência profissional a vida militar). 


\section{Resultados}

5.1 A ida para o lado soft das Forças Armadas:

o ingresso no PDDN

Emergiu nas entrevistas uma diferença que demarca este trabalho do trabalho militar convencional. Em primeiro lugar, porque ele é um trabalho que assenta no contacto com pessoas externas ao mundo militar, com jovens, o que implica competências de comunicação e gestão das emoções que se consideraram extremamente exigentes. Afiguraram-se, nas palavras das várias pessoas entrevistadas, a componente de trabalho emocional ( $\mathrm{Ho}-$ chschild, 2003) e o caráter de forte desgaste emocional que decorre da necessidade de comunicar de forma eficaz com estes jovens, gerir os seus comportamentos e manter o seu interesse e entusiasmo.

Em segundo lugar, emergiu a componente soft deste trabalho que o contrapõe à rigidez e maior tecnicidade do trabalho que faziam em alguns dos ramos, especialmente no Exército, e que cria alguns problemas de adaptação ao Projeto e de articulação entre os desempenhos das pessoas vindas de socializações militares diferentes. Um entrevistado referiu-se mesmo ao maior rigor e rigidez da formação no Exército, que não sentiu refletido nos comportamentos dos seus camaradas dos restantes ramos. Como uma entrevistada tão ilustrativamente referiu, a vinda para o Projeto foi como vir para a "tropa do beijinho":

No início também me custou muito a parte da tropa que eu conhecia. Eu vinha habituada a hierarquias, a continências, aqui é a "tropa do beijinho". Quando integrei o Projeto percebi que o que se tentava fazer era estabelecer a igualdade e as hierarquias não funcionam de forma tão rígida (E3, muIher, 31 anos). 
Sociologias, Porto Alegre, ano 17, no 38, jan/abr 2015, p. 222-253

Ora se este caráter mais comunicacional, relacional e informativo-pedagógico torna este trabalho mais atrativo para algumas pessoas, relativamente à rigidez técnica e disciplinar dos ramos, é também reconhecido que este aspeto contribui para uma certa desvalorização do Projeto e pelo seu menor estatuto no seio da organização militar. Há um sentimento de desvalorização das funções que desempenham, quer na vida civil (como indicam os resultados do questionário, onde 34 pessoas concordam com a afirmação "As minhas funções são pouco valorizadas no mundo laboral" - Tabela 1), quer na instituição militar. Nas entrevistas isto foi apontado como fator de desvalorização do militar, pelo menor estatuto que se reconhece a estas funções:

O nosso trabalho, no PDDN, muito dificilmente é reconhecido pelas instituições militares e vejo isso de uma forma negativa. A forma como as instituições militares, onde pertencemos, veem o nosso trabalho é um pouco negativa. Penso que somos penalizados por sair do ramo e vir para o PDDN, porque ninguém conhece e reconhece as dificuldades do nosso trabalho, têm uma perceção errada (E4, homem, 30 anos).

Esta avaliação será certamente reforçada pelo tipo de relação que mantêm com o pessoal do quadro de pessoal e com as chefias. Este sentimento de menoridade do estatuto das suas funções no âmbito das Forças Armadas constitui também um fator que influirá negativamente na sua satisfação global. Além de sentirem que as funções que desempenham são pouco valorizadas (como mencionado), elas também não servirão no futuro para reforçar a sua empregabilidade no mundo civil, como se vê nos itens 13, 22 e 23, da Tabela 1. 
Tabela 1. Avaliação das condições de trabalho

\begin{tabular}{|c|c|c|c|}
\hline & $\begin{array}{l}\text { Não } \\
\text { se aplica }\end{array}$ & Discordo & Concordo \\
\hline 1. Sinto-me bastante satisfeito com a minha vida profissional & 1 & 18 & 23 \\
\hline 2. Encontro uma verdadeira satisfação nas minhas funções diárias & 1 & 28 & 13 \\
\hline 3. Estou motivado para desempenhar as minhas funções & 1 & 12 & 29 \\
\hline 4. Considero o meu trabalho um desafio & 1 & 22 & 19 \\
\hline $\begin{array}{l}\text { 5. Estar longe de casa tem implicações nas minhas relações } \\
\text { familiares }\end{array}$ & 1 & 6 & 35 \\
\hline 6. Considero-me uma pessoa flexível (desempenho várias tarefas) & 1 & 0 & 41 \\
\hline 7. Adapto-me facilmente a novos contextos profissionais & 1 & 2 & 39 \\
\hline 8. A flexibilidade profissional é importante no mundo laboral & 1 & 1 & 40 \\
\hline $\begin{array}{l}\text { 9. A flexibilidade profissional traz mais desvantagens } \\
\text { que oportunidades }\end{array}$ & 1 & 29 & 12 \\
\hline 10. Gosto de trabalhar sempre com as mesmas pessoas & 1 & 30 & 11 \\
\hline 11. É um desafio trabalhar todos os meses com pessoas diferentes & 1 & 11 & 30 \\
\hline 12. As minhas funções são pobres em conteúdo & 2 & 14 & 26 \\
\hline 13. As minhas funções são pouco valorizadas no mundo laboral & 1 & 7 & 34 \\
\hline $\begin{array}{l}\text { 14. Estou sujeito a condições penosas de trabalho } \\
\text { (riscos de saúde) }\end{array}$ & 3 & 28 & 11 \\
\hline $\begin{array}{l}\text { 15. Tenho fracas ou nulas oportunidades de } \\
\text { qualificação profissional }\end{array}$ & 0 & 18 & 24 \\
\hline $\begin{array}{l}\text { 16. A minha progressão e desenvolvimento estão } \\
\text { limitados na carreira militar }\end{array}$ & 1 & 6 & 35 \\
\hline 17. Tenho um baixo nível de remuneração & 0 & 40 & 2 \\
\hline $\begin{array}{l}\text { 18. Há inadequação da função exercida em } \\
\text { relação às minhas qualificações }\end{array}$ & 2 & 23 & 17 \\
\hline 19. Sinto-me envolvido na organização (sentimento de pertença) & 1 & 13 & 28 \\
\hline 20. Considero uma boa opção a integração na vida militar & 1 & 6 & 35 \\
\hline 21. Considero uma boa opção a integração no projeto DDN & 1 & 10 & 31 \\
\hline $\begin{array}{l}\text { 22. As funções desempenhadas no mundo militar serão } \\
\text { valorizadas no mundo civil }\end{array}$ & 4 & 29 & 9 \\
\hline $\begin{array}{l}\text { 23. A passagem pelo mundo militar vai ajudar-me } \\
\text { a conseguir emprego no mundo do trabalho civil }\end{array}$ & 1 & 31 & 10 \\
\hline
\end{tabular}


Sociologias, Porto Alegre, ano 17, oo 38, jan/abr 2015, p. 222-253

\subsection{Precariedade e satisfação}

Quando foram questionados acerca do seu nível de satisfação em relação a determinados aspetos relacionados, direta e indiretamente, com as funções desempenhadas no PDDN, percebeu-se que a maior insatisfação se refere o caráter temporário do contrato de trabalho. Como Cardoso e colaboradores (2009) concluiram, com o processo de profissionalização das Forças Armadas portuguesas, muitos jovens veem na instituição militar uma oportunidade de emprego, não obstante saberem que a oportunidade é apenas de emprego temporário (por 6 anos). A procura que fazem deste emprego é por isso, tendencialmente instrumental, para aquisição de competências e credenciais associadas à instituição militar. Apesar desta procura instrumental, muitos desenvolvem a ambição de continuidade na vida militar pela possibilidade de concorrerem em alguns ramos, gerando sentimentos de ambivalência de expetativas. De facto, nas entrevistas revelou-se que as pessoas preferiam que existisse a prorrogação do contrato, além dos 6 anos, ou então que os militares contratados usufruíssem de mais oportunidades para ingressar nos quadros permanentes das Forças Armadas.

É uma situação injusta, nós já sabíamos desde a data que entramos nas Forças Armadas que, se não conseguíssemos entrar nos quadros de pessoal, quando acabássemos os 6 anos de contrato não existiam mais hipóteses de continuar. É injusto por ser só 6 anos, porque eu gostaria de continuar, gosto do que faço (E5, mulher, 30 anos).

Refira-se aqui a diferente situação de partida das pessoas dos diferentes ramos. De facto, só nos casos da Força Aérea e da Marinha há a possibilidade explicitada desde início de poderem ingressar nos quadros de pessoal, durante ou após (nos 2 anos seguintes ao abrigo do Regime de Incentivos) o termo do contrato de 6 anos. No Exército essa possibilidade não existe, não se criando expetativas. A precariedade do vínculo contratual é, portanto, o aspeto mais problemático das condições de trabalho 
destas pessoas, ou como refere Paugam (2000) a precariedade de emprego, remetendo estas pessoas para a certeza de descontinuidade e necessidade de encontrar outro trabalho, findo o contrato. Apesar de conhecerem logo à partida esta condição de precariedade, como se evidenciou também no item 16 da Tabela 1, muitas das pessoas consideraram-na uma injustiça, tendo em conta o seu empenhamento na organização e as dificuldades que anteveem na transição para um mercado de trabalho em crise aguda como o atual. A aproximação do fim do contrato desencadeia um turbilhão de sentimentos:

É uma situação complicada, porque, quando faltava algum tempo para eu terminar o contrato e quando via os outros divulgadores a chegar a altura deles saírem, começava a ver esse pessoal a desmotivar e já farto e com aquela atitude mais desleixada: "deixa, também já estou para me ir embora, já não estou para me chatear". Eu não percebia isso muito bem, somos profissionais, cumprimos com as nossas obrigações até ao final, no entanto, a forma de trabalhar e de estar perante as situações, do pessoal que estava a terminar o contrato, já era completamente diferente. Hoje, compreendo essa situação, porque é um trabalho e um esforço inglório. É complicado, fiquei, por um lado, triste, não só pela situação que o país atravessa agora, a instabilidade económica e a dificuldade em arranjar trabalho, mas também porque vou deixar uma atividade e pessoas com quem trabalhava há alguns anos. Quando se chega à reta final é que conseguimos perceber realmente o quanto é difícil gerir estes sentimentos (E2, mulher, 33 anos).

Outro motivo de insatisfação relacionado com a precariedade, desta vez não apenas de emprego, mas de trabalho (Paugam, 2000), prende-se com os défices de formação interna proporcionada pela organização, e que contrasta com a formação proporcionada aos militares com contrato permanente: como somos contratados, não investem muito em formação para nós, para depois termos mais-valias lá fora. (E3, mulher, 31 anos). 
Sociologias, Porto Alegre, ano 17, no 38, jan/abr 2015, p. 222-253

Assim se destacou uma diferença sentida por estes "trabalhadores da periferia" relativamente aos "trabalhadores do núcleo duro", como nomeou Harvey (1996).

Face a esta lacuna na formação e desenvolvimento proporcionado, a estratégia de muitas pessoas entrevistadas é a de autoformação permanente, típico de uma era de "trabalhadores portfólio" (Wooldridge, 2012). Também aqui o desenvolvimento e melhoria profissional assumem-se como sendo da responsabilidade individual, devendo para isso empenhar-se pessoalmente no seu autoaperfeiçoamento. A autoformação e o interesse pelo trabalho são vistos como uma responsabilidade pessoal e individual destes profissionais que "devem" tornar interessantes as apresentações e palestras.

Uma das queixas mais significativas que emergiram nas entrevistas e que se afigurou como um dos fatores de insatisfação ao nível da precaridade no trabalho foi o caráter repetitivo, monótono e rotineiro do trabalho, em termos de conteúdo. Também Boene (2009) assinalou estas caraterísticas e queixas por parte dos profissionais das Forças Armadas na Europa, podendo constituir um fator determinante de intenções de saída. Considera-se que é um trabalho monótono, repetitivo e que subaproveita as competências de quem o integra, assentando em atividades pouco enriquecedoras:

Apesar de podermos melhorar e de rodarmos de tarefas, é repetitivo, é muito repetitivo, dia após dia e sempre as mesmas coisas. Psicologicamente cansa, satura, temos de saber gerir bem a parte psicológica (E1, homem, 31 anos).

Julgo ter mais competências. Quero desenvolver mais competências e desenvolvendo mais competências, não tenho aqui espaço para as aplicar, as competências que tenho e as que quero ter (E6, mulher, 27 anos). 
Sociologias, Porto Alegre, ano 17, no 38, jan/abr 2015, p. 222-253

Esta última oficial revelou a insatisfação com a estagnação a que se sente sujeita. Como se verifica na Tabela 1, é geral a insatisfação nas funções executadas (item 2 da Tabela), devido ao seu pobre conteúdo (item 12).

Outro aspeto que dificulta a satisfação prendeu-se com as deslocações mensais e os seus impactos, essencialmente em termos de desgaste, despesas, instabilidade familiar, dificuldades de conciliação e de fazer formação pós-graduada.

Um dos aspetos que se destacou também negativamente foi o relacionamento com as chefias hierárquicas marcado pela distância, falta de apoio e de contacto. Algumas pessoas disseram mesmo existir da parte das chefias um profundo desconhecimento do "trabalho que realizam no terreno", fator de desconsideração e desvalorização:

Gostaríamos de ter mais vezes a presença das nossas chefias ao pé das equipas de divulgação. Por vezes, sentimo-nos afastados de tudo. Nós já nos afastamos demasiado do ramo quando integramos o Projeto, precisamos de ter um epicentro que nos segure e nos ampare. Gostaríamos de ter mais próxima a opinião, a mensagem das chefias. Penso que deveríamos ter mais apoio da parte da supervisão (E4, homem, 30 anos).

Este sentimento de distanciamento das chefias e os défices de comunicação top-bottom agravou o sentimento de insegurança, numa altura que ouvem declarações políticas falando em reestruturações do PDDN. 
Sociologias, Porto Alegre, ano 17, no 38, jan/abr 2015, p. 222-253

Tabela 2. Aspetos negativos do trabalho

\begin{tabular}{l|c|c}
\hline & Ocorrências & $\%$ \\
\hline Trabalho monótono & 13 & 16,7 \\
\hline Mau comportamento da parte dos jovens & 3 & 3,8 \\
\hline Desleixo de alguns membros da equipa & 11 & 14,1 \\
\hline Deslocações constantes (muitas horas de viagem) & 19 & 24,4 \\
\hline Falta de condições físicas e materiais (alojamento, alimentação) & 1 & 1,3 \\
\hline Trabalho pouco enriquecedor em conhecimentos & 12 & 15,4 \\
\hline Contrato com termo certo & 8 & 10,3 \\
\hline Inexistência de perspetivas de carreira & 10 & 12,8 \\
\hline Outros & 1 & 1,3 \\
\hline
\end{tabular}

Outra queixa decorreu do sentimento de falta de autonomia e de participação na organização e no trabalho, que algumas das pessoas entrevistadas veem como fazendo parte da forma como funciona a vida militar, assente em relações hierárquicas e de poder (ordens). As mulheres queixaram-se deste aspeto, muito presente na vida militar e, como salienta Goudswaard e Nanteuil (2000), isto deve-se essencialmente às atuais práticas de flexibilidade que menosprezam a flexibilidade funcional, ou seja, o enfraquecimento das estruturas hierárquicas, a polivalência e a rotação de tarefas:

A vida militar tem aspetos fantásticos, mas também tem aspetos pré-históricos. A hierarquia, as questões hierárquicas, por vezes, são levadas de forma extrema. Existe sim autoritarismo, exagero e um certo machismo relacionado com o passado militar vincadamente masculino (E6, mulher, 27 anos).

Globalmente, concluiu-se que vários são os fatores que impendem negativamente sobre a satisfação das pessoas, que se relacionam com dimensões de flexibilidade (mobilidade geográfica) e de precariedade de trabalho (conteúdo de trabalho monótono e repetitivo, pouco adequado 
Sociologias, Porto Alegre, ano 17, no 38, jan/abr 2015, p. 222-253

a competências possuídas, reduzidas possibilidades de enriquecimento profissional, por exemplo, via formação).

\subsection{Segmentação entre núcleo duro e periferia}

Na comparação que fizeram com os militares dos quadros permanentes, os membros do PDDN consideraram como principais diferenças entre ambos o facto de "serem mais recetivos a aceitar tarefas" $(88,1 \%)$; a diferença no estatuto social que este tipo de vínculo contratual confere $(85,7 \%)$ e especificamente pelo sentimento de menoridade do estatuto das suas funções (menos visibilidade) no âmbito das Forças Armadas; o menor acesso a formação profissional (90,5\%); e o reconhecimento de que as exigências são maiores e há menor tolerância em casos de erro (69,1\%). Em termos de condições físicas e remuneratórias não foram assinaladas diferenças significativas.

\subsection{Implicações da mobilidade geográfica mensal}

Relativamente às implicações da mobilidade geográfica mensal mais significativamente identificadas, foi destacado o afastamento de casa e da família e o desgaste emocional que esse afastamento provoca. Para além do desgaste emocional, o afastamento de casa implica sobrecarga da família, no apoio de retaguarda, especialmente na resolução de assuntos burocrático-administrativos. As dificuldades de conciliação da vida familiar, pessoal e profissional são assim um dos principais sintomas e impactos da mobilidade geográfica.

É complicado, muito complicado, gerir uma casa, ter uma família, estar presente em momentos importantes, organizar as limpezas, a lista de compras e as pessoas com quem estamos compreenderem a nossa situação. Uma mulher nestas condições de trabalho tem mais complicações, as suas responsabilidades sociais são diferentes das dos homens, apesar de agora os homens já se dedicarem mais (E6, mulher, 27 anos). 
Sociologias, Porto Alegre, ano 17, no 38, jan/abr 2015, p. 222-253

Existe um reconhecimento generalizado de que a condição de mobilidade geográfica tem implicações mais significativas para as mulheres. Estas dificuldades levaram algumas das pessoas entrevistadas a afirmar que este é um trabalho que se adequa mais aos homens do que às muIheres. Surgiram nas entrevistas conceções de género muito essencialistas e que reforçam os estereótipos e papéis de género, com as pessoas entrevistadas a vincularem as maiores dificuldades de conciliação das mulheres à sua "natural" ligação às funções reprodutivas e afetivas:

\begin{abstract}
Se for uma mulher a ter um filho, eu penso que se a pessoa não conseguir ficar num Centro mais perto de casa, ai vai ter muitas dificuldades. Uma mulher mãe que está neste tipo de trabalho poderá ter mais dificuldades, porque é muita coisa sobre ela, porque é a mulher que amamenta e só pode ser a mãe, o coordenar os banhos, claro que aqui já pode ter a ajuda do marido, mas há sempre mais responsabilidades sobre a mãe. Uma mulher mãe tem responsabilidades sociais diferentes das do homem, deveriam ser iguais, mas ainda há tendência para a mulher se preocupar mais, se calhar por questões da natureza, é que uma criança passa 9 meses no ventre da mãe (E1, homem, 31 anos).
\end{abstract}

Um aspeto positivo que se destacou nas entrevistas relativamente a este assunto da conciliação foi o reconhecimento de que a instituição procura ajustar as condições de trabalho às necessidades de conciliação, particularmente, nas situações de necessidades familiares específicas (nascimento de crianças, gravidez...): uma camarada nossa estava grávida e teria que ir trabalhar algum tempo para os Açores, seria uma situação complicada para ela, ela explicou a situação em que se encontrava e isso foi tido em conta e ela não foi (E6, mulher, 27 anos).

Mas é uma atenção que fica no informal, dando azo a equívocos e sentimentos de que há pessoas que são privilegiadas. Não existe, portanto, uma cultura organizacional promotora da conciliação ou family-friendly, o que limitará a perceção de capacidade para utilização de direitos 
ligados à conciliação e à parentalidade, por parte das pessoas deste grupo periférico. Assim, muitas adiam os projetos pessoais e familiares, como o de constituir família e de comprar casa, tendendo a tudo relativizar devido à "vida de inconstâncias":

O aspeto mais difícil de conciliar é o facto de não ter um local fixo. Quero ter a minha casa, não posso. Falando especificamente no meu caso, quero ter um filho, não posso. $O$ pai e a mãe andam de um lado para o outro, é tudo muito instável e depois vou adiando. Agora andava com a ideia de comprar casa com o meu namorado, mas devido a todas estas incertezas de saber como é que o Projeto se vai desenrolar, se vai reestruturar, já pusemos de parte essa ideia, pelo menos, por enquanto. É tudo muito vago e vou adiando os meus projetos de vida pessoal (E8, mulher, 28 anos).

Outro tipo de implicações negativas da mobilidade são as dificuldades em investir na formação e no desenvolvimento da carreira, para reforço da empregabilidade futura.

Preocupa-me, porque o facto de eu estar no Projeto faz com que eu todos os meses mude de cidade, de sítio de trabalho. Temos de fazer viagens diferentes, com horários diferentes. Nós damos muito de nós ao Projeto, temos o nosso retorno como é óbvio em termos de experiência e ordenado, mas nada mais. Quando eu penso no que vou fazer depois disto, fico preocupado, porque é mais difícil para mim fazer formações, porque estou em cidades diferentes todos os meses. A formação tirada à distância não é solução. Mas o facto de termos de andar sempre de cidade em cidade, faz com que eu me preocupe e não tenha o tempo e a disponibilidade para tirar, por exemplo, um mestrado, uma pós-graduação, uma formação, um curso (E4, homem, 30 anos). 
Sociologias, Porto Alegre, ano 17, oo 38, jan/abr 2015, p. 222-253

$5.5 \mathrm{Na}$ antecâmara para a flexibilidade/adaptabilidade no mundo laboral civil

Apesar de se manifestarem insatisfeitos/as com a precariedade do seu vínculo laboral temporário e com algumas caraterísticas das suas condições de trabalho, na realidade, foi possível constatar um reconhecimento, por parte das pessoas inquiridas, de que aquelas se inscrevem quase que inevitavelmente nas caraterísticas dominantes do mercado de emprego atual. Globalmente, manifestou-se uma consciência da flexibilidade laboral como pano de fundo das situações profissionais na atualidade. A ideia do emprego para toda a vida e perto da área de residência começa a cair em desuso e as pessoas estão conscientes disso.

Nas entrevistas foi possível registar uma certa adaptação à mobilidade e precariedade como marcas das trajetórias profissionais na atualidade e a tentativa de fazer do fim do contrato "algo de positivo", verificando-se a adaptação à instabilidade como um esforço de interiorização individual à retórica da adaptabilidade, como concluíram outros estudos (Marques, 2009).

\begin{abstract}
A minha opinião acerca de um trabalho que implica mobilidade geográfica reflete uma vida cansativa, fatigante, mas ajuda-nos a enriquecer, a ser mais jovens, a ser mais versáteis a adaptarmo-nos a novas realidades. Obviamente que é uma condição muito importante no mercado de trabalho e nos dias que correm. Se eu disser a um chefe, numa empresa, no mundo civil, que estou disponível para trabalhar onde a empresa precisa de alguém para trabalhar, a pessoa tira as suas próprias conclusões e nós temos esta facilidade, porque estamos habituados a ela, porque já sentimos na pele as vantagens e as desvantagens, as agonias e as alegrias (E4, homem, 30 anos).
\end{abstract}

A mobilidade instala-se como forma de vida e a autoformação, empreendedorismo, empregabilidade, inovação, criatividade, voluntarismo e a proatividade surgem como atitudes consideradas desejáveis num mer- 
cado de emprego altamente competitivo e num cenário de autogestão do percurso profissional (Gangl, 2002; Marques, 2009; Rose, 1998). Ora, se isto implica uma individualização e responsabilização pelo percurso, implica também um assumir-se empreendedor de uma reversibilidade e reconversão permanentes de percursos formativos, centrada na capacidade de reconstruir projetos de vida, acumular experiências profissionais e formativas num labor de "empregabilidade" permanente.

Nós, na Europa, ainda temos essa opinião de que nós vamos construir uma casa, família, vamos para o trabalho durante o dia e regressamos à noite. Isto tem tendência a acabar, e já está a acontecer; nós, europeus, vamos ficar cada vez mais adaptados a esse tipo de realidade, ver apenas a nossa família ao fim de semana. (E4, homem, 30 anos)

Quando questionados sobre os planos profissionais futuros fora da instituição militar, maioritariamente, estas pessoas pretendem encontrar trabalho na sua área de formação (50\%) e outras manifestam a intenção de emigrar, procurando um mercado de trabalho mais recetivo e com mais oportunidades (16,7\%). Para muitos, a estratégia de preparação para o mercado de trabalho passa pela atenção a possibilidades de emprego, fazer formação, reforçar as redes sociais informais e explorar apoios ao empreendedorismo. A idade com que saem das Forças Armadas, que é superior aos trinta anos, é considerada um fator que impende negativamente sobre a sua inserção no mercado de trabalho.

\section{Conclusões}

Foi possível constatar que a situação profissional destes militares é marcada quer pela precariedade de emprego, devido ao vínculo contratual temporário, quer pela precariedade no trabalho, para a qual contribuem a realização de um trabalho repetitivo, monótono e pouco enriquecedor em 
Sociologias, Porto Alegre, ano 17, oo 38, jan/abr 2015, p. 222-253

termos de conhecimentos, com expetativas de carreira ou de progressão socioprofissional praticamente inexistentes. A precariedade evidenciada está relacionada com as condições de trabalho, nomeadamente, o desempenho de funções de pobre conteúdo, por vezes, pouco valorizadas no mundo organizacional e até mesmo no meio militar onde são executadas, confirmando assim a segunda hipótese do estudo e evidenciando as dimensões heuristicamente utilizadas por Paugam (2000) no que respeita à precariedade no trabalho e no emprego. As mesmas conclusões foram identificadas por Boene (2009) relativamente a outros países europeus.

Espelhou-se também, com o estudo, a segmentação no interior das Forças Armadas portuguesas entre oficiais do quadro permanente e os oficiais contratados, emergindo desigualdade entre os profissionais do "centro" e os da "periferia" (Harvey, 1996). As desigualdades mais significativas estão associadas à falta de oportunidades de formação e de desenvolvimento de competências; à maior disponibilidade para aceitar todo o tipo de tarefas; às exigências acrescidas e a menor tolerância ao erro para os contratados; ao baixo estatuto destas funções do PDDN nas Forças Armadas, porque assentam em tarefas de comunicação e de formação de jovens, falando-se mesmo numa "tropa do beijinho" e agravando o sentimento de falta de apoio por parte das chefias. Existe o reconhecimento de que os militares da periferia têm de ser mais flexíveis e recorrer a autoformação e autoaperfeiçoamento, validando a quarta hipótese. Ou seja, não obstante partilharem com os militares do quadro o estatuto de militar e igualdade em termos de algumas condições materiais de trabalho (remuneração), existe um sentimento de desigualdade entre os militares contratados ("periferia") e os dos quadros permanentes ("centro"), com dimensões materiais e simbólicas específicas essencialmente ligadas à precariedade do vínculo e diferença estatutária dentro das Forças Armadas.

Conclui-se que a mobilidade acarreta vários impactos, salientando-se o desgaste emocional da distância à família e amigos, e as dificuldades 
Sociologias, Porto Alegre, ano 17, no 38, jan/abr 2015, p. 222-253

de conciliação e de fazer formação que possa reforçar a empregabilidade de cada um. Este impacto da mobilidade é mais reconhecido pelo sexo feminino devido às maiores dificuldades de conciliação (sobressaindo a ideia de que as mulheres têm tarefas sociais e familiares adicionais e diferentes das dos homens), verificando-se assim uma desigualdade entre os sexos, que valida a hipótese seis.

Em quarto lugar, conclui-se que o caráter voluntário de algumas formas de trabalho flexível, como é o caso de alguns dos elementos da equipa estudada (que voluntariamente solicitaram a integração neste trabalho) não as desvinculam do epíteto de trabalho precário; antes revelam uma escolha condicionada por fatores que fazem dela "do mal o menos" face a um mercado de trabalho que exclui os jovens e os relega para trabalhos flexíveis e bastante mal pagos, parecendo esta "precariedade" do PDDN melhor do que "as outras". As razões que condicionam e justificam esta opção passam principalmente pela remuneração auferida, tal como identificado em outros estudos (Boene, 2009). Assim se verificou que estas pessoas interiorizam uma identidade de trabalhadores descartáveis (Fialho et al., 2011) ou nómadas (Boltanski e Chiapello, 1999) e que se acomodam à ideia de precariedade existente no contexto laboral atual, mesmo que seja por um período determinado, validando desta forma a terceira hipótese.

Também foi confirmada a quinta hipótese, já que as circunstâncias vivenciadas pelos membros do PDDN impossibilitam a definição de um percurso profissional coerente e identitário, sendo a instabilidade articulada com um sentimento de necessidade de adaptação constante e empregabilidade permanentes, originando um individualismo-fragilização de seres isolados submetidos à insegurança, desfiliação e fragilização do laço social e das relações sociais (Kóvacs, 2005).

Por fim, na reflexão que fazem acerca da sua situação, os militares do PDDN apresentaram juízos complexos acerca desta experiência pro- 
Sociologias, Porto Alegre, ano 17, oo 38, jan/abr 2015, p. 222-253

fissional, conjugando dimensões de ganho, nomeadamente o emprego, a remuneração e alguns benefícios auferidos numa época de escassez destes bens; com dimensões de perda, tendo em conta a fragilidade do vínculo contratual, a mobilidade geográfica permanente, e a instabilidade e dificuldades de conciliação, sendo certamente jovens marcados por incertezas, riscos e ganhos temporários, que vivem sentimentos contraditórios de querer permanecer no PDDN, mas ao mesmo tempo preferirem um trabalho estável e valorizado, confirmando assim a hipótese um.

Esta ambivalência de expectativas é um dos efeitos do processo de profissionalização que tem acontecido nas Forças Armadas em muitos países europeus (Boene, 2009; Cardoso et al., 2009). O trabalho nas Forças Armadas, não obstante ser concebido como uma "passagem" transporta consigo um conjunto de racionalidades que impõem uma maior atenção à forma como a instituição militar gere os seus recursos humanos. Esta gestão tem de acomodar sentimentos de desvalorização e de precarização, essencialmente ao nível de grupos periféricos como o aqui estudado, com estratégias de motivação e empenhamento para o desempenho das funções atribuídas. Como outros estudos salientam (Boene, 2009), constatou-se que as remunerações continuam a ser o principal fator satisfatório para os profissionais das Forças Armadas, que reconhecem a vantagem comparativa, sendo mesmo o seu elemento fundamental de atratividade. Os desafios para a organização militar são bastantes, com uma força de trabalho que tende a apresentar-se desmoralizada pela precariedade, pela sensação de rotina, fadiga e impossibilidade de progressão. Para os indivíduos, a consciência de trabalhador nómada começa a pesar com as deslocações constantes, com a aproximação do fim do contrato e com a necessidade de preparação para a reintegração no mercado de trabalho. A precariedade de emprego e de trabalho oferecidas pelo trabalho no PDDN caraterizam um setor que era dos mais estruturados e que garantia permanência e estabili- 
dade de carreira, o militar, sendo agora também um local de passagem dos seus profissionais. Por estas razões, parecem justificar-se as recomendações (Boene 2009) para que sejam criados e disponibilizados serviços de reinserção profissional (formação, outplacement, aconselhamento profissional), pelas Forças Armadas, que permitam não só a integração no mercado de trabalho, mas também a readaptação à vida civil.

Rosa Monteiro - Doutora em sociologia, investigadora no Centro de Estudos Sociais da Universidade de Coimbra. Professora do Instituto Superior Miguel Torga, nos domínios do trabalho e da Gestão de Recursos Humanos. Vice-presidente da Associação Portuguesa de Estudos sobre as Mulheres. $\backslash$ monteiro.rosa14@gmail.com

Sónia Oliveira - Mestre em Gestão de Recursos Humanos e Comportamento Organizacional. Instituto Superior Miguel Torga, Coimbra. $M$ margaridaoliveira21@gmail.com

Fernanda Daniel - Doutora em Psicologia (Desenvolvimento e Intervenção Psicológica); Investigadora no Centro de Estudos e Investigação em Saúde CEISUC - Faculdade de Economia da Universidade de Coimbra. Professora do Instituto Superior Miguel Torga na área da estatística e da metodologia. $\$ fernanda.b.daniel@gmail.com

\section{Referências}

1. ANDERSON, Michael, BECHHOFER, Frank, JAMIESON, Lynn, MCCRONE, David, LI, Yaojun e STEWART, Robert Stewart. Confidence Amid Uncertainty: Ambitions and Plans in a Sample of Young Adults. Sociological Research Online, 6(4), 2002.

2. BARBIER, Jean-Claude. A survey of the use of the term precarité in French economics and sociology. Paris: CNRS. 2002

3. BECK, Ulrich. Brave New World of Labour. Cambridge: Polity Press, 2000.

4. BOENE, Bernard. Shifting to All-Volunteer Armed Forces in Europe: Why, How, With What Effects? Fórum Sociológico, 19, 2009, p. 49-60.

5. BOLTANSKI, Luc e CHIAPELLO, Eve. Le Nouvel Esprit du Capitalisme. Paris: Éd. Gallimard, 1999. 
Sociologias, Porto Alegre, ano 17, no 38, jan/abr 2015, p. 222-253

6. BOYER, Robert. La Flexibilité du Travail en Europe - une étude comparative des transformations du rapport salarial dans sept pays de 1973 à 1985. Paris: Éd. Découverte, 1986.

7. CABRAL, Arlinda. Conciliação ou conflito entre o trabalho e as outras esferas da vida social na inserção profissional dos diplomados do ensino superior. Ricot Journal, 1, 2011, p. 68-97.

8. CARDOSO, Ana. Organização e intensificação do tempo de trabalho. Sociedade e Estado, 28(2), 2013, p. 351-374.

9. CARDOSO, António., MADEIRA, Isabel, MARQUES, Francisco e VILHENA, Cristina. A profissionalização das Forças Armadas: um olhar sobre o seu pilar de sustentação - os militares do regime de voluntariado e de contrato. Fórum Sociológico, 19, 2009, p. 37-48.

10. CARLSON, Dawn e KACMAR, Michele. Work-family conflict in the organization: do life roles values make a difference? Journal of Management, 26, 2000, p. 1031-1054.

11. CASACA, Sara. Flexibilidade, trabalho e emprego - ensaio de conceptualização. [Working Paper, 10]. ISEG-UTL, 2005.

12. CASTEL, Robert. Les Métamorphoses de la Question Sociale: une chronique du salariat. Paris: Fayard, 1995.

13. CASTELLS, Manuel. A sociedade em rede. São Paulo: Paz e Terra, 1999.

14. COPPIN, Laura e VANDENBRANDE, Tom. Mobility and career development of professionals and managers. Bruxelas: Eurocadres, 2007.

15. FIALHO, José, SILVA, Carlos e SARAGOÇA, José. Trabalho e dilemas nas relações laborais: valores, perspectivas e expectativas. Revista Educação Skepsis, I (2), 2011, p. 33-60.

16. FRONE, Michael. Interpersonal conflict at work and psychological outcomes: testing a model among young workers. Journal of Occupational Health Pychology, 5, 2000, p. 246-255.

17. GANGL, Markus. Changing labour markets and early career outcomes: labour market entry in Europe over the past decade. Work, Employment and Society, 2002, p. 67-90.

18. GOUDSWAARD, Anneke e NANTEUIL, Matthieu. Flexibility and Working Conditions. A Qualitative and Comparative Study in Seven EU Member States. Bruxelas: EFILWC, 2000.

19. GREEN, Anne E. e CANNY, Angela. Geographical Mobility: Family impacts. Bristol: Policy Press, 2003. 
20. GRZYWACZ, J., ALMEIDA, D. e MCDONALD, D. Work-family spillover and daily reports of work and family stress in the adult labor force. Family Relations, 47, 2002, p. 255-266.

21. HARVEY, D. Condição pós moderna: uma pesquisa sobre as origens da mudança cultural. São Paulo: Edições Loyola, 1996.

22. HOCHSCHILD, Arlie. The Managed Heart. Commercialization of Human Feeling. Berkeley: University of California Press, 2003.

23. KOVÁCS, Illona. Flexibilidade de emprego - Riscos e Oportunidades. Oeiras: Celta, 2005.

24. KOVÁCS, Illona. Flexibilização do mercado de trabalho e percursos de transição de jovens: uma abordagem qualitativa do caso da área metropolitana de Lisboa. [Working Paper, 1], ISEG-UTL, 2013.

25. KOVÁCS, Illona.; CASACA, Sara. Flexibilidad y desigualdad en el trabajo: tendencias y alternativas europeas. Sociologia del Trabajo, 61, 2007, p. 99-124.

26. MARQUES, Ana Paula. Trajectórias Quebradas. A vivência do desemprego. Porto: Profedições, 2009.

27. PAUGAM, Serge. Le Salarié de la Precarité. Paris: PUF, 2000.

28. PEDACI, Marcello. The flexibility trap: temporary jobs and precarity as a disciplinary mechanism. Journal of Labor and Society, 13, 2, 2010, p. 245-262.

29. ROSE, J. Les jeunes et l'emploi. Paris: Desclée de Brouwer, 1998.

30. SEGAL, Mady. Women's Military Roles Cross-Nationally: past, present, and future. Gender \& Society, 9, 1995, p. 757-775.

31. TILLY, Charles. Migration in Modern European History. Michigan: Univ. of Michigan, 1976.

32. WOOLDRIDGE, Adrian. Os Senhores da Gestão: como os gurus de negócio e as suas ideias mudaram o mundo para melhor (ou pior). Rio de Janeiro: Elsevier, 2012.

Recebido em: 01/08//2014

Aceite Final: 26/11/2014 